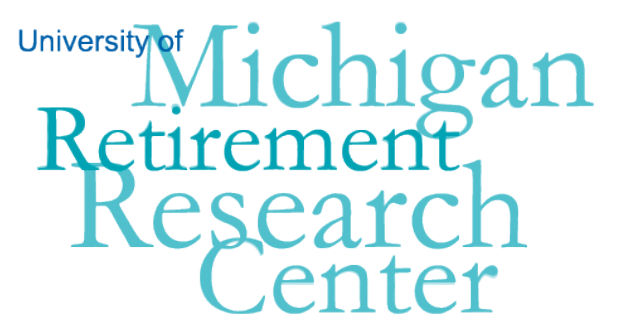

Working Paper WP 2013-303

\title{
Uncovering the Relationship between Real Interest Rates and Economic Growth
}

\author{
Bruce E. Hansen and Ananth Seshadri
}

\begin{tabular}{|l|l|}
\hline $\mathrm{M}$ & $\mathrm{R}$ \\
\hline $\mathrm{R}$ & $\mathrm{C}$ \\
\hline
\end{tabular}

Project \#: UM13-Q1 



\title{
Uncovering the Relationship between Real Interest Rates and Economic Growth
}

\author{
Bruce E. Hansen
}

Ananth Seshadri

University of Wisconsin-Madison

December 2013

\author{
Michigan Retirement Research Center \\ University of Michigan \\ P.O. Box 1248 \\ Ann Arbor, MI 48104 \\ www.mrrc.isr.umich.edu
}

(734) 615-0422

\section{Acknowledgements}

This work was supported by a grant from the Social Security Administration through the Michigan Retirement Research Center (Grant \# 5 RRC08098401-05-00). The findings and conclusions expressed are solely those of the author and do not represent the views of the Social Security Administration, any agency of the Federal government, or the Michigan Retirement Research Center.

\section{Regents of the University of Michigan}

Mark J. Bernstein, Ann Arbor; Julia Donovan Darlow, Ann Arbor; Laurence B. Deitch, Bloomfield Hills; Shauna Ryder Diggs, Grosse Pointe; Denise Ilitch, Bingham Farms; Andrea Fischer Newman, Ann Arbor; Andrew C. Richner, Grosse Pointe Park ;

Katherine E. White, Ann Arbor; Mary Sue Coleman, ex officio 


\title{
Uncovering the Relationship between Real Interest Rates and Economic Growth
}

\begin{abstract}
We analyze long-span data on real interest rates and productivity growth with the focus on estimating their long-run correlation. The evidence points to a moderately negative correlation, meaning that real interest rate is mildly countercyclical, although the estimates are not precise. Our best estimate of the long-run correlation is 0.20. The implications for long-term projections are as follows. A negative correlation implies that long-run costs due to a period of low interest rates will tend to be slightly offset by a period of high productivity growth. Conversely, long-run benefits during a period of high interest rates will be offset by low productivity growth. This implication is consistent with the question raised in the Project Solicitation concerning why the trust fund stochastic simulations tend to show less long-run variability than do the alternative assumption projections. We also examine the implications for the variability of long-term projections of trust fund accumulation. As expected, we find that a negative correlation reduces the variability in the stochastic intervals. However, our simplified calculations suggest that the effect is modest.
\end{abstract}

\section{Citation}

Hansen, Bruce E., and Ananth Seshadri (2013). "Uncovering the Relationship between Real Interest Rates and Economic Growth.” Ann Arbor MI: University of Michigan Retirement Research Center (MRRC) Working Paper, WP 2013-303. http://www.mrrc.isr.umich.edu/publications/papers/pdf/wp303.pdf 


\section{Introduction}

This paper examines the long-run relationship between real interest rates and productivity growth. The goal is to assess the long-run correlation between the two variables, and make recommendations concerning the alternative assumptions for the Trustees Report.

The organization of this paper is as follows. We start with a brief review of the relevant economic theory. We then review existing empirical studies. Next, we describe the long-span data we gathered for our analysis. The following section describes the relationship between longrun projections, variances, and correlations. Following this, we describe our estimation methods. The next section describes the empirical results, including our main results and our sensitivity analysis. The final section analyzes the implications for Trust Fund projections.

\section{Brief Review of Theory}

The relationship between real interest rates and growth rates has long interested economists. Here we briefly mention two theories that have predictions for the relationship.

McKinnon-Shaw: According to McKinnon (1973) and Shaw (1973), financial repression arises when a country imposes a ceiling on deposit. They conclude that alleviating financial restrictions and letting market forces determine real interest rates leads to higher real interest rates. The higher real rates of return lead to higher levels of savings, which in turn spur economic growth. Hence, the prediction from their framework is that real interest rates and growth rates are positively related.

Barro-Becker: Barro and Becker (1989) consider a model with endogenous fertility choice. As is well known, in the standard growth model, real interest rates are given by the inverse of the discount factor in a steady state. Barro and Becker posit a discount factor function that depends on the birth rate of the economy. As a result, there is a long-run relationship between real interest rates and fertility rates. Over the long-run, as fertility rates decline, so do real rates of return. This model predicts a negative relationship between real interest rates and economic growth. In most macroeconomic models, there is a one for one relationship between real interest rates and the discount factor (this is a statement about preferences or the utility function). Needless to say, 
unless preferences change, long-term rates do not change. What Barro and Becker did was to configure children into the preference side whereby the rate of discounting is affected by the number of children. From this, it follows directly that there is a one for one relationship between real interest rates and fertility rates and a negative relationship between real interest rates and economic growth.

\section{Brief Review of Evidence}

Despite the significance of the topic, there is not much work trying to ascertain the relationship between real rates of return and economic growth. There is a large literature on the effect of financial liberalization on growth. These studies use measures of financial development such as the degree of public ownership of banks, size of intermediaries and the like and attempt to provide a causal relationship between these variables and economic growth.

A paper by D’Adda and Scorcu (1997) looks at data on 20 industrialized countries over the period 1965-94. When possible, they use average interest rates on long term government bonds. They find a negative relationship between real rates of return and economic growth. Clearly, the horizon they consider is shorter than would be ideal for purposes of long-term analysis.

Given the paucity of work on the topic, we next turn to a systematic investigation of the long-run relationship between these important variables.

\section{Data}

Our goal was to use the longest available U.S. time-series data for real interest rates, labor productivity, real earnings growth, and real aggregate GDP growth. We constructed several series which span 1901-2011. All our series are annual.

\section{Real Interest Rates}

Real interest rates for OASDI Trust Fund New Issues are reported in Table 5.3 of The LongRange Economic Assumptions for the 2012 Trustees Report (1938-2010) and The Long-Range Economic Assumptions for the 2013 Trustees Report (1962-2011), which we merged to obtain a series for 1938-2011. 
Nominal interest rates on long-term U.S. government bonds from 1871 have been gathered by Robert Shiller and are posted on his website. To convert these rates to real rates, we subtracted a CPI inflation rate (percentage change in the CPI index) constructed to match the OASDI real rates. For the period 1952-2011 we used the Adjusted CPI-W index from Table 2.3 of The LongRange Economic Assumptions for the 2012 Trustees Report. For 1914-1951 we used the CPI-W index from the Bureau of Labor Statistics, and for 1901-1913 we used the CPI index from Shiller's data file. Notice that we merged the measured inflation, not the CPI indices.

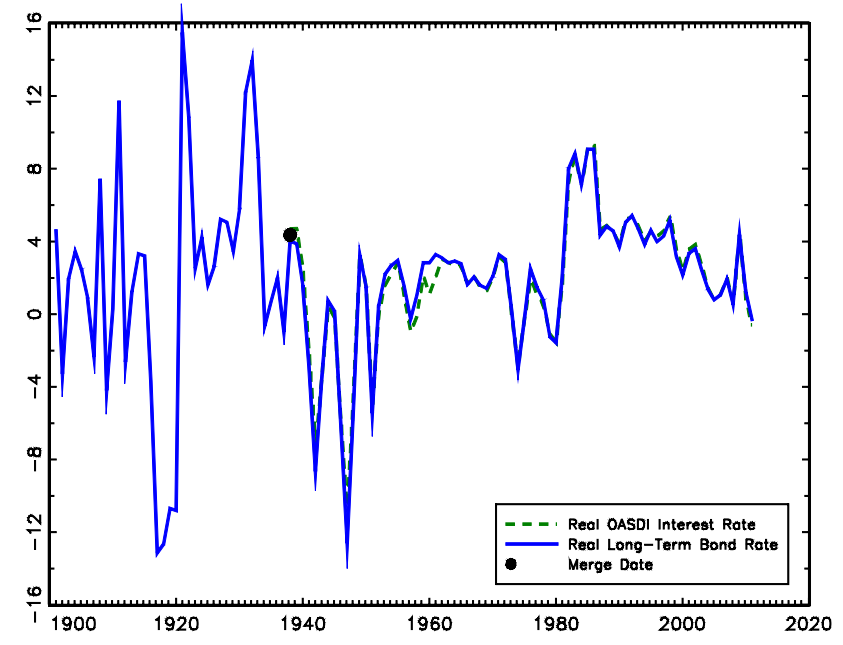

Figure 1: Real Interest Rates

We plot these two real interest rate series in Figure 1. It is difficult to distinguish one from the other. A nonparametric estimate of their long-run correlation (described in the section on Estimation Methods) for the overlapping sample period 1938-2011 is 0.99, indicating that the two are close substitutes. We combine the two series into a single series for 1901-2011, using the long-term real bond rates for 1901-1937 and the OASDI real interest rates for 1938-2011.

\section{Productivity}

An index of productivity in the nonfarm business sector is reported in Table 1.5 of The LongRange Economic Assumptions for the 2012 Trustees Report (1951-2010) and The Long-Range Economic Assumptions for the 2013 Trustees Report (1961-2011). Taking annual percentage changes, we created a growth series for 1952-2011. 
Total Factor Productivity is reported in Historical Statistics (Series W6) for 1900-1948. This was merged with the Multifactor Productivity Index (nonfarm business) from the BLS to create a growth series for 1901-2000.

The two series are plotted in Figure 2. They match fairly well for most of the overlapping sample period, and have an estimated long-run correlation of 0.86 . We combine the two series into a single series for 1901-2011, using Historical Statistics/BLS for 1901-1951 and the SSA series for 1952-2011.

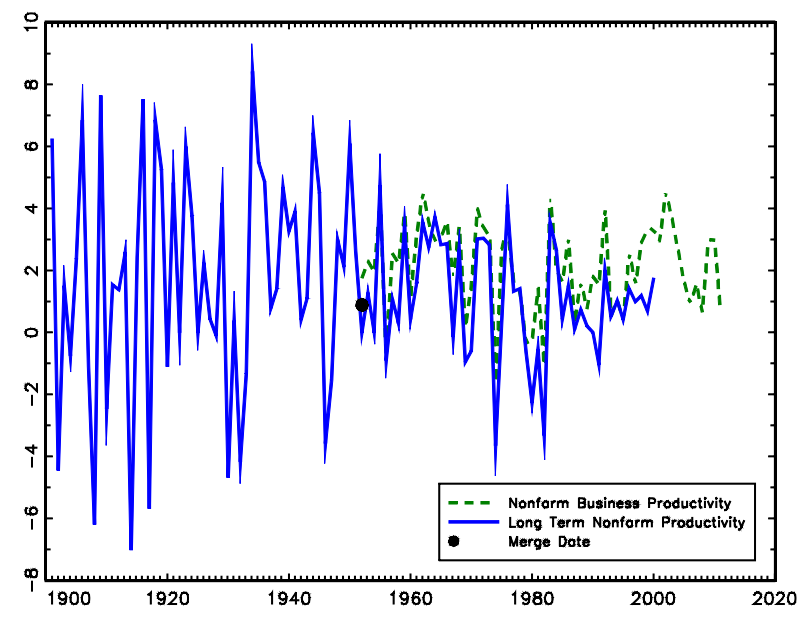

Figure 2: Nonfarm Business Productivity

We retain the SSA 1952-2011 series and the 1901-2000 series for subsample analysis.

An index of total-economy productivity is reported in Table 1.4 of The Long-Range Economic Assumptions for the 2012 Trustees Report (1951-2010) and The Long-Range Economic Assumptions for the 2013 Trustees Report (1961-2011). Taking annual percentage changes, we created a growth series for 1952-2011. We do not have a long-span version of this series. We retained the total-economy productivity series for subsample analysis.

\section{Real Earnings Growth}

The SSA model includes the real-wage differential (the growth rate in average real covered wages). Nominal average total earnings in OASDI covered employment per worker is available in Table 4.B1 of the Annual Statistical Supplement, 2012 for the years 1950-2011. Dividing by 
the Adjusted CPI-W index, and then converting to growth rates, we obtained the real-wage differential for 1952-2011.

A long-span index of real wages was created by Williamson (1995) for 1900-1988, which we used to create a growth series for 1901-1988.

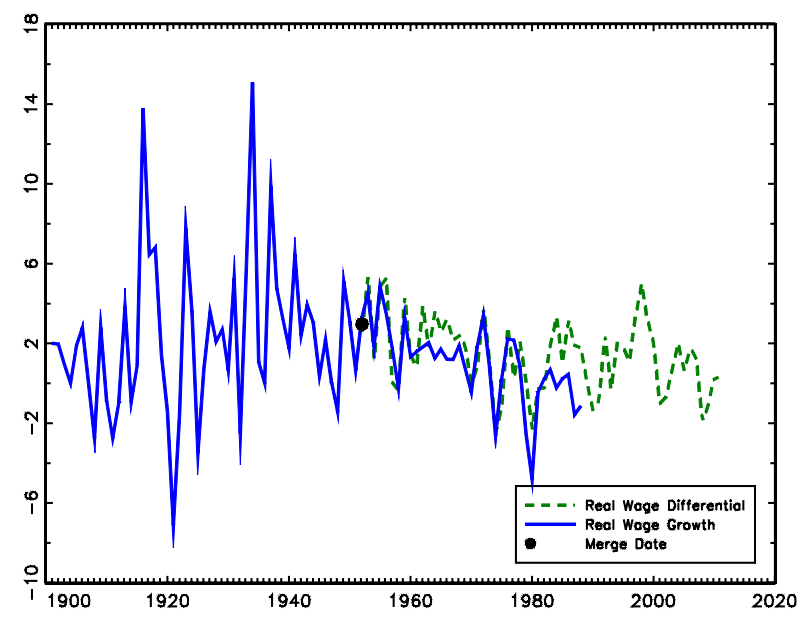

Figure 3: Real Wage Differential

The two series are plotted in Figure 3. They match well at the beginning of the overlapping sample, and have a nonparametric long-run correlation of 0.78 . To create a long-range series we combine the two series, using the long-span real wage growth series for 1901-1951 and the realwage differential for 1952-2011.

\section{Real GDP Growth}

Annual percentage growth in real GDP is available from the Bureau of Economic Analysis for 1930-2011.

\section{Data Summary}

We have long-span series for real interest rates and three distinct measures of economic growth. In addition we have five sub-sample measures of economic growth. The series and sample periods are listed in Table 1. 
Table 1: Data summary

\begin{tabular}{|l|l|l|}
\hline & Long span & Alternative sample periods \\
\hline Real Interest Rate & $1901-2011$ & \\
\hline Nonfarm Business Productivity & $1901-2011$ & $1901-2000,1952-2011$ \\
\hline Total-Economy Productivity & & $1952-2011$ \\
\hline Real Wage Growth & $1901-2011$ & $1901-1988,1952-2011$ \\
\hline Real GDP Growth & $1930-2011$ & \\
\hline
\end{tabular}

\section{Long-run Projections, Variance, and Correlation}

Some of the key inputs for the long-term projections in the Trustees Report are the future values of interest rates and economic growth. The uncertainty in these projections is largely determined by the long-run variances and correlations of these variables.

To understand these issues it will be helpful to use some mathematical notation. Let denote the real interest rate and let denote economic growth in year $t$. To a first approximation the Trust Fund projection $T$ years ahead is determined by the long-term averages ${ }^{-}=\frac{1}{-} \sum=1 \quad$ and $-{ }^{-}=\frac{1}{-} \sum_{=1}$. Consequently, the uncertainty in the projection is determined by the variances and covariances of of ${ }^{-}$and $^{-}$. These are long-run variances, and are quite different from conventional variances due to serial correlation.

The (asymptotic) long-run (co)variance matrix for $=(, \quad)^{\prime}$ is

$$
=\lim _{\rightarrow \infty}\left[\begin{array}{cc}
\left({ }^{-}\right) & \left({ }^{-},-\right) \\
\left(^{-},-\right) & \left(\left(^{-}\right)\right.
\end{array}\right]
$$

This equals

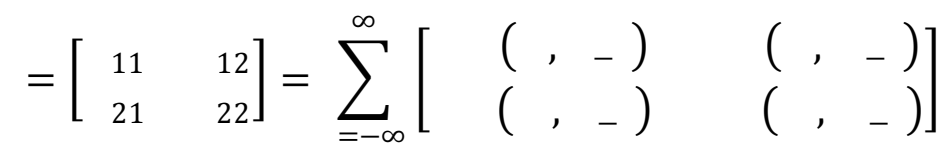


The long-run correlation is

$$
=\frac{21}{\sqrt{2211}}=\lim _{\rightarrow \infty} \frac{\left(^{-},,^{-}\right)}{\sqrt{\left(^{-}\right)\left(^{-}\right)}}
$$

The long-run correlation summarizes the extent to which the long-term averages ${ }^{-}$and ${ }^{-}$are correlated and summarizes the extent to which the costs of possible low interest rates or economic growth may be naturally offset.

It is, therefore, the primary goal of this project to estimate the long-run correlation between real interest rates and real economic growth.

\section{Estimation Methods}

Estimates of the long-run correlation are constructed from estimates of the long-run covariance matrix, and there are two well-established approaches for the latter: (1) Nonparametric; and (2) Vector Autoregressive (VAR). We use both methods.

\section{Nonparametric Long-Run Covariance Estimation}

Nonparametric kernel estimators were introduced to econometrics by Newey and West (1987) as a generalization of the covariance matrix estimators of Hansen and Hodrick (1980) and Hansen (1982). They are also known as HAC (heteroskedasticity-and-autocorrelation-consistent) covariance matrix estimators. The estimate of the covariance matrix is a weighted average of estimated covariances, where the long lags are downweighted according to a weighting (kernel) function. Given a sample of length $n$, the estimators take the form

$$
\hat{\imath} \sum_{=-}(-)^{-} \sum_{=1}\left(-{ }^{-}\right)\left(+{ }^{-}\right)^{\prime}
$$

The number $M$ is called the lag truncation number and the weight function $w$ is called the kernel. Our calculations use the Parzen kernel.

The critical issue is how to select the lag truncation number, as this determines the amount of weighting on long covariance lags. Empirical methods to select $M$ have been developed by Andrews (1991) and Newey and West (1994), with the current state-of-the-art appearing in 
Hirukawa (2010). We use Hirukawa’s SP (solve-the-equation plug-in) rule and computer code to select $M$.

Given , the long-run correlation estimate is constructed as

$$
\hat{\imath}=\frac{\widehat{21}}{\sqrt{\widehat{\widehat{11} 22}}}
$$

\section{Vector Autoregressive (VAR) Long-Run Covariance Estimation}

The long-run covariance matrix can be written as a function of the coefficients of a VAR model. $A \operatorname{VAR}(\mathrm{p})$ model for $=(,)^{\prime}$ is

$$
=\quad+\quad \begin{array}{llllll}
-1 & + & 2 & -2 & +\cdots+ & +
\end{array}
$$

with mean zero and covariance matrix $\Sigma$. In this model, the long-run covariance matrix for equals

$$
=\left(-{ }_{1}-{ }_{2}-\cdots-\right)^{-1} \Sigma\left(-{ }_{1}-2-\cdots-\right)^{-1}
$$

The VAR long-run covariance matrix estimate replaces the unknowns by the estimates from a fitted VAR.

Specifically, we estimate the VAR coefficients using ordinary least-squares (OLS)

$$
=\wedge+{ }^{\wedge}{ }_{1}-1+{ }^{\wedge} 2-2+\cdots+{ }^{\wedge}-+^{\wedge}
$$

with the covariance estimated as

$$
\widehat{\Sigma}=\frac{1}{\sum_{=1}} \wedge
$$

The estimates of and are then

$$
\hat{\imath}=\left(-\wedge_{1}-\wedge_{2}-\cdots-{ }^{\wedge}\right)^{-1} \widehat{\Sigma}\left(-\wedge_{1}-\wedge_{2}-\cdots-{ }^{\wedge}\right)^{-1}
$$

and 


$$
\hat{\imath}=\frac{\widehat{21}}{\sqrt{\widehat{\widehat{1122}}}}
$$

The critical issue is how to select the number of VAR lags $p$. The estimates can be sensitive to this choice. We select $p$ by minimizing the Akaike Information Criterion (AIC) across VAR models from 1 to 4 . AIC selection is a highly regarded method for time-series specification, as it produces estimates which properly balance bias and variance to minimize the mean-squared error of parameter estimates (in this case the long-run correlation).

\section{Assessing Parameter Estimation Uncertainty}

To assess the precision of our correlation estimates, we report standard errors and $90 \%$ confidence intervals calculated by the bootstrap. In principle, asymptotic standard errors could be calculated, but they are unlikely to be accurate for the long-run correlations due to the strong nonlinearity in their construction. For our bootstrap method we generate bivariate data from an estimated VAR(4), and making 10,000 simulated samples. On each simulated sample the longrun correlation is estimated using the above methods (incorporating lag selection). The standard deviation of the estimates across the 10,000 samples is the bootstrap standard error, and the bootstrap confidence interval is formed using the 5\% and 95\% empirical quantiles from the 10,000 correlation estimates. (This is known as the percentile bootstrap method.)

\section{Empirical Results}

\section{Estimates of Long-Run Correlation}

Our main estimates of the long-run correlation are reported in Table 2. Estimates are reported for our three long-span measures of economic growth: Nonfarm business productivity (19012011), real wage growth (1901-2011), and real GDP growth (1930-2011). Point estimates, standard errors, and $90 \%$ bootstrap confidence intervals are reported. To reduce the variation, we also average the estimates across estimation methods and series.

All six point estimates are negative, ranging from -0.09 to -0.25 , though none are statistically significant from zero. (All six confidence intervals are wide and include zero.) The estimates do 
not greatly differ from one another, and have an average value of -0.20 . This is our best estimate of the long-run correlation.

Table 2: Estimates of Long-run Correlation

\begin{tabular}{|l|l|l|l|l|}
\hline & $\begin{array}{l}\text { Sample } \\
\text { Period }\end{array}$ & NonParametric & VAR & Average \\
\hline Nonfarm Business Productivity & $1901-2011$ & -0.19 & -0.25 & -0.22 \\
\hline & & $(0.20)$ & $(0.23)$ & \\
\hline & & {$[-0.47,0.18]$} & {$[-0.59,0.17]$} & \\
\hline & & & & \\
\hline Real Wage Growth & $1901-2011$ & -0.16 & -0.19 & -0.17 \\
\hline & & $(0.18)$ & $(0.29)$ & \\
\hline & & {$[-0.42,0.16]$} & {$[-0.62,0.32]$} & \\
\hline Real GDP Growth & & & & -0.20 \\
\hline & $1930-2011$ & -0.32 & -0.09 & \\
\hline & & $(0.24)$ & $(0.38)$ & \\
\hline & & {$[-0.47,0.32]$} & {$[-0.66,0.56]$} & \\
\hline Average & & & & -0.20 \\
\hline
\end{tabular}

Note: Estimates are of the long-run correlation of real interest rates with each measure of real economic growth. Bootstrap standard errors are in parenthesis (from 10,000 replications), and the brackets are 90\% bootstrap percentile confidence intervals.

We report estimates from the alternative sub-samples in Table 3. The estimates are more varied than in Table 2. The standard errors and confidence intervals are larger, indicating the imprecision of long-run parameters estimation in short samples. The results do not cause us to alter the inferences from Table 2.

What do these estimates imply? The estimated long-run standard deviation of real interest rates is about 8 , productivity growth is 2.4, real wage growth 3.5 and real GDP growth 4.5. The expected long-run change in real interest rates given a 1 percentage point increase in long-run output growth (e.g. from $2 \%$ to $3 \%$ ) is the correlation (-0.2), multiplied by the standard deviation of real interest rates (8), divided by the standard deviation of growth (2.4, 3.5, or 4.5$)$. Thus, the 
expected long-run change in real interest rates given a 1 percentage point increase in productivity growth is a decrease of 67 basis points, given a 1 percentage point increase in real wage growth is a decrease of 46 basis points, and given a 1 percentage point increase in real GDP growth is a decrease of 36 basis points. Conversely, given an increase in real interest rates by 100 basis points, the expected long-run change in the productivity growth rate is $-.2 \mathrm{x}(2.4) / 8=-0.06$ (e.g. from $2.00 \%$ to $1.94 \%$ ) the expected long-run change in the real wage growth rate is -0.09 , and the expected long-run change in the real GDP growth rate is -0.11 .

Since real GDP growth is one of the primary objects of primary interest to you, if all of a sudden we were to experience an increase in the trend growth rate by 1 percentage point, real interest rates would fall by 36 basis points. 
Table 3: Subsample Estimates of Long-run Correlation

\begin{tabular}{|c|c|c|c|}
\hline & $\begin{array}{l}\text { Sample } \\
\text { Period }\end{array}$ & NonParametric & Vector Autoregressive \\
\hline \multirow[t]{3}{*}{ Nonfarm Business Productivity } & $1901-2000$ & -0.27 & -0.35 \\
\hline & & $(0.19)$ & $(0.23)$ \\
\hline & & {$[-0.53,0.11]$} & {$[-0.67,0.08]$} \\
\hline \multirow[t]{3}{*}{ Nonfarm Business Productivity } & $1952-2011$ & -0.05 & -0.44 \\
\hline & & $(0.30)$ & $(0.44)$ \\
\hline & & {$[-0.38,0.62]$} & {$[-0.83,0.63]$} \\
\hline \multirow[t]{3}{*}{ Total Economic Productivity } & $1952-2011$ & -0.24 & -0.62 \\
\hline & & $(0.32)$ & $(0.43)$ \\
\hline & & {$[-0.46,0.61]$} & {$[-0.89,0.50]$} \\
\hline \multirow[t]{3}{*}{ Real Wage Growth } & 1901-1988 & -0.27 & -0.40 \\
\hline & & $(0.18)$ & $(0.29)$ \\
\hline & & {$[-0.52,0.05]$} & {$[-0.76,0.18]$} \\
\hline \multirow[t]{3}{*}{ Real Wage Growth } & $1952-2011$ & 0.11 & 0.24 \\
\hline & & $(0.25)$ & $(0.34)$ \\
\hline & & {$[-0.13,0.67]$} & {$[-0.39,0.73]$} \\
\hline
\end{tabular}

\section{Sensitivity Analysis}

We performed some sensitivity analyses. First, we estimated the long-run correlation using Vector Autoregressions of fixed order from 1 to 4, and report the results in Table 4. (In contrast, Tables 2 and 3 report the VAR estimate from the AIC-selected model.) The point estimates vary across VAR order, in particular for the GDP series. The fact that the estimates vary across VAR order is not (in itself) surprising, as there is no reason for estimates to be stable across misspecified models. This illustrates the need for an appropriate model-selection method such as the 
AIC. (The models/estimates selected by AIC are indicated by an asterisk.) Even though the estimates vary across VAR order, all of the point estimates are negative, and most do not vary too greatly.

Table 4: VAR Estimates of Long-run Correlation

\begin{tabular}{|l|l|l|l|}
\hline & Nonfarm Productivity & Real Wage Growth & Real GDP Growth \\
\hline VAR(1) & $-0.25^{*}$ & -0.20 & -0.33 \\
\hline VAR(2) & -0.20 & -0.09 & -0.09 \\
\hline VAR(3) & -0.37 & $-0.19^{*}$ & -0.09 \\
\hline VAR(4) & -0.32 & -0.23 & $-0.09^{*}$ \\
\hline
\end{tabular}

Note: AIC-selected model marked with an asterisk (*).

Second, we assessed sensitivity to the 1980s, when money supply growth was severely targeted by the Federal Reserve Board in an attempt to sharply reduce inflation, and real interest rates spiked. We assess sensitivity by including a dummy variable for the years 1981-1989 in the VAR estimates. The point estimates from Table 2 are essentially unchanged. The point estimates for the post-war series from Table 3 are more greatly affected (the estimate for nonfarm productivity becomes positive at 0.16 ) but these estimates are imprecise with very large standard errors. We conclude that once placed in the context of long-span data, our point estimates are not driven by the unusual rates of the 1980s.

Third, we applied tests for structural change to the VAR estimates. We applied the SupF test of Andrews (1993) to each regression equation (each VAR has two equations) and assessed statistical significance using the heteroskedasticity-robust fixed regressor bootstrap of Hansen (2000). Of the six regressions from Table 2, one test is statistically significant at the $1 \%$ level, another is significant at the $5 \%$ level, and the remaining four are statistically insignificant. A statistically significant test means that we can reject the hypothesis of constant regression coefficients during the sample period. Two of six rejections is moderate evidence of coefficient instability, but unsurprisingly mild given the long time spans for the series. The practical implication of coefficient instability can be assessed by examining the subsample estimates. As these are not inconsistent with our full sample estimates, we believe the latter are the best measure for the long-run correlation. 


\section{VAR Estimates}

For completeness, we report our estimates of the selected VAR models in Table 5.

Table 5: VAR Estimates

\begin{tabular}{|c|c|c|c|c|c|c|}
\hline & \multicolumn{2}{|c|}{ Nonfarm Productivity } & \multicolumn{2}{|c|}{ Real Wage Growth } & \multicolumn{2}{|c|}{ Real GDP growth } \\
\hline Intercept & $\begin{array}{c}1.45 \\
(0.89)\end{array}$ & $\begin{array}{c}2.19 \\
(0.38)\end{array}$ & $\begin{array}{c}1.99 \\
(0.85)\end{array}$ & $\begin{array}{c}0.54 \\
(0.50)\end{array}$ & $\begin{array}{c}0.30 \\
(0.70)\end{array}$ & $\begin{array}{c}2.90 \\
(1.57)\end{array}$ \\
\hline-1 & $\begin{array}{c}0.53 \\
(0.15)\end{array}$ & $\begin{array}{c}-0.00 \\
(0.07)\end{array}$ & $\begin{array}{c}0.52 \\
(0.17)\end{array}$ & $\begin{array}{c}0.06 \\
(0.10) \\
\end{array}$ & $\begin{array}{c}1.02 \\
(0.22)\end{array}$ & $\begin{array}{c}0.21 \\
(0.33) \\
\end{array}$ \\
\hline-1 & $\begin{array}{c}-0.31 \\
(0.23)\end{array}$ & $\begin{array}{c}-0.14 \\
(0.13)\end{array}$ & $\begin{array}{l}-0.35 \\
(0.20)\end{array}$ & $\begin{array}{c}0.29 \\
(0.11)\end{array}$ & $\begin{array}{c}-0.01 \\
(0.14)\end{array}$ & $\begin{array}{c}0.56 \\
(0.22)\end{array}$ \\
\hline-2 & & & $\begin{array}{c}-0.18 \\
(0.11)\end{array}$ & $\begin{array}{c}0.20 \\
(0.09) \\
\end{array}$ & $\begin{array}{c}-0.60 \\
(0.19)\end{array}$ & $\begin{array}{c}-0.36 \\
(0.45)\end{array}$ \\
\hline-2 & & & $\begin{array}{c}-0.10 \\
(0.13)\end{array}$ & $\begin{array}{c}-0.15 \\
(0.15)\end{array}$ & $\begin{array}{c}0.11 \\
(0.12)\end{array}$ & $\begin{array}{c}-0.11 \\
(0.18)\end{array}$ \\
\hline-3 & & & $\begin{array}{l}-0.19 \\
(0.13)\end{array}$ & $\begin{array}{c}-0.04 \\
(0.08)\end{array}$ & $\begin{array}{c}0.23 \\
(0.16)\end{array}$ & $\begin{array}{c}0.52 \\
(0.42)\end{array}$ \\
\hline-3 & & & $\begin{array}{c}-0.16 \\
(0.12)\end{array}$ & $\begin{array}{c}0.34 \\
(0.14) \\
\end{array}$ & $\begin{array}{c}-0.25 \\
(0.11)\end{array}$ & $\begin{array}{c}-0.04 \\
(0.25)\end{array}$ \\
\hline-4 & & & & & $\begin{array}{c}0.10 \\
(0.14)\end{array}$ & $\begin{array}{c}-0.30 \\
(0.24)\end{array}$ \\
\hline-4 & & & & & $\begin{array}{c}0.16 \\
(0.08) \\
\end{array}$ & $\begin{array}{c}-0.20 \\
(0.22) \\
\end{array}$ \\
\hline$\widehat{\widehat{\Sigma}}$ & {$\left[\begin{array}{c}16.1 \\
-0.67\end{array}\right.$} & $\left.\begin{array}{c}-0.67 \\
7.77\end{array}\right]$ & {$\left[\begin{array}{c}15.6 \\
-3.16\end{array}\right.$} & $\left.\begin{array}{c}-3.16 \\
7.67\end{array}\right]$ & {$\left[\begin{array}{r}4.9 \\
-2.5\end{array}\right.$} & $\left.\begin{array}{c}-2.52 \\
13.3\end{array}\right]$ \\
\hline
\end{tabular}

Note: Robust standard errors in parenthesis. refers to the real interest rate, to the measure of economic growth (nonfarm productivity, real wage growth, or real GDP growth).

\section{Implications for Trust Fund Accumulations}

In this section we discuss the implications of our estimates for assessing uncertainty in trust fund projections. Our calculations suggest that a negative long-run correlation reduces the variability of long-run projections. However, the effect does not appear to be large.

We illustrate using a crudely simplified model of Trust Fund accumulation. Let denote income, let denote the income growth rate, let denote the interest rate, let denote payouts, and let denote the Trust Fund. Assume that the variables evolve according to

$$
=-1(1+/ 100)+-
$$




$$
\begin{aligned}
& ={ }_{-1}(1+/ 100) \\
& ={ }_{-1}(1+/ 100)
\end{aligned}
$$

The first equation states that the Trust Fund earns interest plus new income less payouts. The second states that income grows at growth rate , and the third equation states that payouts growth at fixed growth rate .

We normalize ${ }_{0}=1$, set ${ }_{0}=1, \quad 0=4$, and $=3$. We model $=(, \quad)^{\prime}$ as a VAR(1), using the VAR(1) parameters and covariance matrix for real interest rates and nonfarm business productivity reported in the first two columns of Table 5, but make the adjustment that the mean values are set equal to the intermediate assumptions from the Trustees Report for real interest rates and total economy productivity (that is, a mean interest rate of 2.9 and a mean growth rate of 1.68).

We project forward 50 years by simulation, and display in Figure 4 the Trust Fund ratios (the ratio of the Trust Fund to the cost $\quad$ ) at the $50^{\text {th }}$ percentile (the solid line), and at the $97.5^{\text {th }}$ and $2.5^{\text {th }}$ percentiles (the dotted lines). While our model is a very crude approximation to the actual Trust Fund projection, Figure 4 is similar in character to the stochastic simulations reported in Figure VI.E4 of Appendix E from the 2013 Annual Report. For example, the Trust Fund in the median projection is depleted in year 25, with a 90\% confidence interval of 17 to 42 years. 


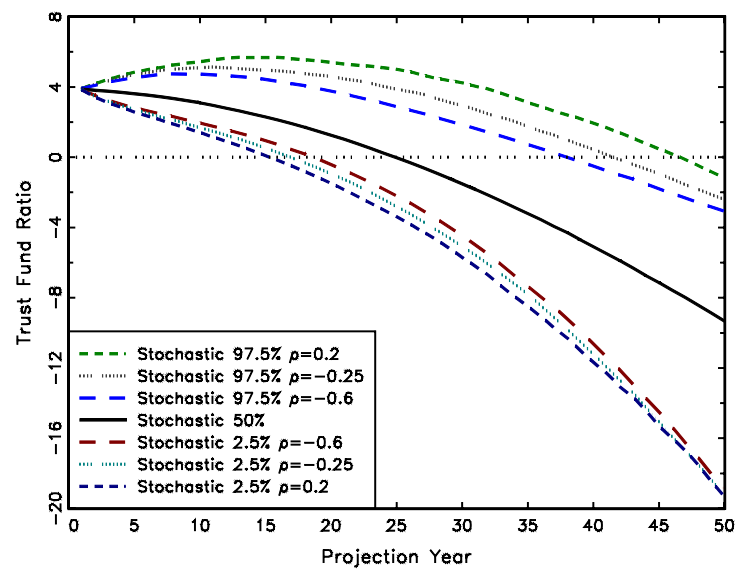

Figure 4: Trust Fund Projections: Comparison of Long-Run Correlations

We are interested in the role of the long-run correlation . Recall that the VAR estimate of is -0.25 (from Table 2). This is the effective value in this simulation, since we are using the parameters of the estimated VAR. Table 2 shows that a $90 \%$ confidence interval for is approximately $[-0.6,0.2]$. We alter the VAR innovation covariance matrix $\sum$ so that equals these values (first -0.6 and then 0.2 ) by adjusting $\sum$ so that the long-run variances are unchanged. We repeat the simulation, and display in Figure 4 the Trust Fund ratios at the $97.5^{\text {th }}$ and $2.5^{\text {th }}$ percentiles with the long dashes $(=-0.6)$ and the short dashes $(=0.2)$.

As expected, negative correlations yield less variable (shorter) confidence intervals, and positive correlations yield wider intervals. However, the differences are modest. With the most negative correlation ( $=-0.6$ ), the 95\% confidence interval for Trust Fund depletion is 19 to 39 years, yet with the most positive correlation ( $=0.2$ ), the 95\% interval is widened to 16 to 47 years.

\section{Replication}

All files and data for the numerical calculations reported in this paper are available at http://www.ssc.wisc.edu/ bhansen/progs/ssa_project.zip . The calculations were done in Excel and Gauss. Excel was used for preliminary data sorting and Gauss for the statistical calculations and simulations. 


\section{References}

Barro, R.J., and Becker, G.S. 1989 . “Fertility Choice in a Model of Economic Growth,” Econometrica 57, 481-501.

Andrews, Donald W.K., 1991. "Heteroskedasticity and autocorrelation consistent covariance matrix estimation,” Econometrica, 59, 817-858.

Andrews, Donald W.K., 1993. “Tests for parameter instability and structural change with unknown change point,” Econometrica, 61, 821-856.

C. D. Adda \& A.E. Scorcu, 1997. “Real Interest Rate and Growth: An Empirical Note,” Working Papers 276, Dipartimento Scienze Economiche, Università di Bologna.

Hansen, Bruce E., 2000. “Testing for structural change in conditional models,” Journal of Econometrics, 97, 93-115.

Hansen, Lars Peter and R.J. Hodrick, 1980. “Forward Exchange-Rates as Optimal Predictors of Future Spot Rates - An Econometric-Analysis,” Journal of Political Economy, 88, 829853.

Hansen, Lars Peter, 1982. “Large sample properties of Generalized Method of Moments estimators, Econometrica, 50, 1029-1054.

Hirukawa, Masayuki, 2010. “A Two-Stage Plug-in Bandwidth Selection and its Implementation for Covariance Estimation,” Econometric Theory, 26, 710-743.

McKinnon Ronald .I (1973). Money and Capital in Economic Development. Washington, D.C.: Brookings Institution.

Newey, W.K. and K.D. West, 1987. “A simple, positive semi-definite, heteroskedasticity and autocorrelation consistent covariance matrix estimator,” Econometrica, 55, 703-708. 
Newey, W.K. and K.D. West, 1994. “Automatic lag selection in covariance matrix estimation,” Review of Economic Studies, 61, 631-653.

“Annual Statistical Supplement to the Social Security Bulletin, 2012” SSA Publication No. 1311700, February 2013.

“The Long-Range Economic Assumptions for the 2012 Trustees Report,” Office of the Chief Actuary, Social Security Administration, April 23, 2012.

“The Long-Range Economic Assumptions for the 2013 Trustees Report,” Office of the Chief Actuary, Social Security Administration, May 31, 2013.

"The 2013 Annual Report of the Board of Trustees of the Federal Old-Age and Survivors Insurance and the Federal Disability Insurance Trust Funds,” May 31, 2013.

Shiller, Robert. Online Data, posted at http://www.econ.yale.edu/ shiller/data.htm. Accessed 07/01/2013.

Shaw E (1973). Financial Deepening in Economic Development. New York: Oxford University Press.

United States Bureau of the Census, 1975. Historical Statistics of the United States, Colonial Times to 1970. Washington, DC: U.S. Dept. of Commerce, Bureau of the Census. Williamson, Jeffrey G. (1995): “The Evolution of Global Labor Markets since 1930: Background Evidence and Hypotheses,” Exploration in Economic History, 32, 141-196. 